Review

\title{
Small Molecule Tyrosine Kinase Inhibitors of ErbB2/HER2/Neu in the Treatment of Aggressive Breast Cancer
}

\author{
Richard L. Schroeder ${ }^{1}$, Cheryl L. Stevens ${ }^{2}$ and Jayalakshmi Sridhar ${ }^{1, *}$ \\ 1 Department of Chemistry, Xavier University of Louisiana, 1 Drexel Drive, New Orleans, \\ LA 70125, USA; E-Mail: rschroed@xula.edu \\ 2 Ogden College of Science and Engineering, Western Kentucky University, 1906 College Heights \\ Boulevard \#11075, Bowling Green, KY 42101, USA; E-Mail: cheryl.stevens@wku.edu \\ * Author to whom correspondence should be addressed; E-Mail: jsridhar@xula.edu; \\ Tel.: +1-504-520-7519 (ext. 123); Fax: +1-504-520-7942.
}

Received: 6 August 2014; in revised form: 8 September 2014 / Accepted: 10 September 2014 / Published: 23 September 2014

\begin{abstract}
The human epidermal growth factor receptor 2 (HER2) is a member of the erbB class of tyrosine kinase receptors. These proteins are normally expressed at the surface of healthy cells and play critical roles in the signal transduction cascade in a myriad of biochemical pathways responsible for cell growth and differentiation. However, it is widely known that amplification and subsequent overexpression of the HER2 encoding oncogene results in unregulated cell proliferation in an aggressive form of breast cancer known as HER2-positive breast cancer. Existing therapies such as trastuzumab (Herceptin ${ }^{\circledR}$ ) and lapatinib (Tyverb/Tykerb ${ }^{\circledR}$ ), a monoclonal antibody inhibitor and a dual EGFR/HER2 kinase inhibitor, respectively, are currently used in the treatment of HER2-positive cancers, although issues with high recurrence and acquired resistance still remain. Small molecule tyrosine kinase inhibitors provide attractive therapeutic targets, as they are able to block cell signaling associated with many of the proposed mechanisms for HER2 resistance. In this regard we aim to present a review on the available HER2 tyrosine kinase inhibitors, as well as those currently in development. The use of tyrosine kinase inhibitors as sequential or combinatorial therapeutic strategies with other HER family inhibitors is also discussed.
\end{abstract}

Keywords: human epidermal growth factor 2 (HER2); kinase domain; HER2 inhibition; monoclonal antibodies; small molecule inhibitors 


\section{Introduction}

Breast cancer is among the most commonly diagnosed cancers worldwide and is the number one cancer found in women, with an estimated 14.1 million cases reported in 2012 [1]. Overexpression of the human epidermal growth factor receptor 2 (HER2) is responsible for nearly $15 \%-30 \%$ of breast cancers, and is generally associated with poor patient survival [1-3]. HER2 is a 185-kDa transmembrane protein encoded by the erbB2 oncogene located on chromosome 17q21-22 [1]. It is a member of the erbB class of receptor tyrosine kinases consisting of four homologous proteins: HER1 (EGFR/ErbB1), HER2 (ErbB2/Neu), HER3 (ErbB3), and HER4 (ErbB4). Normal expression of these proteins at the cell surface is essential for regulating cell growth and epithelial cell survival. However, amplification and overexpression of the HER2 oncogene is typically seen in aggressive metastatic breast cancer, though it is also observed in other malignancies as well [4]. In addition to neglected locally advanced cancers and metastases of low-stage breast cancer, factors such as the rate of proliferation or the ER status of the tumor are related to the recurrence. It has been suggested that prolonged treatment with tamoxifen and/or longer duration of treatment are better at reducing recurrence and prolonging survival than shorter duration $[5,6]$.

Structurally, the HER family consists of an extracellular growth factor ligand-binding domain, a lipophilic alpha helical transmembrane region, and a catalytically active intracellular tyrosine kinase domain. Members of the HER family, with the exception of HER2, have been shown to exhibit ligand specificity (Table 1), where ligand binding induces receptor homodimerization or heterodimerization. Receptor dimers allow intracellular autophosphorylation of specific tyrosine residues within the catalytic kinase domain [7]. The activated dimer complex triggers important downstream cell signaling pathways such as mitogen-activated protein kinase (MAPK), phosphatidylinositol-3 kinase (PI3K)/Akt, phospholipase $C \gamma$, and protein kinase $C$ among others [8,9]. There are no known natural ligands that bind to HER2 specifically. HER2 is known to be a preferred dimerization partner forming potent heterodimers with EGFR and HER3 despite its inability for direct ligand interaction [10].

Table 1. Known growth factor ligands and their associated erbB receptors.

\begin{tabular}{ccccc}
\hline Growth Factor & EGFR & HER2 & HER3 & HER4 \\
\hline Amphiregulin & + & - & - & - \\
Betacellulin & + & - & - & + \\
Epiregulin & + & - & - & + \\
Epigen & + & - & - & - \\
Epidermal Growth Factor (EGF) & + & - & - & - \\
Heparin-binding EGF-like Growth Factor (HB-EGF) & + & - & - & + \\
Transforming Growth Factor alpha (TGF- $\alpha$ ) & + & - & - & - \\
Neuregulin-1 (NRG1) & - & - & + & + \\
Neuregulin-2 (NRG2) & - & - & + & + \\
Neuregulin-3 (NRG3) & - & - & - & + \\
Neuregulin-4 (NRG4) & - & - & - & + \\
\hline
\end{tabular}

A $100-115 \mathrm{kDa}$ truncated form of HER2 (p95 ${ }^{\mathrm{HER} 2}$ ) is expressed in nearly $30 \%$ of HER2-positive breast cancers and contains a series of carboxy-terminal fragments [11,12]. Despite lacking an 
extracellular domain, $\mathrm{p} 95^{\mathrm{HER} 2}$ still triggers proliferative downstream signaling events and forms potent heterodimers due to its active kinase region [12]. The lack of an extracellular domain prohibits ligand targeting antibody therapies from interacting with the protein and promotes a cause of resistance for such drugs. However, since $\mathrm{p} 95^{\mathrm{HER} 2}$ contains an active kinase domain it remains susceptible to kinase inhibition and serves as an important target in overcoming antibody resistant therapies. Small molecule tyrosine kinase inhibitors are covered extensively in the literature [13-21], however an emphasis on the recent applications and the developing therapeutic benefits regarding erbB2 inhibition in the last 5-10 years of clinical studies are reported herein.

\section{Monoclonal Antibodies in HER2 Inhibition}

\subsection{Trastuzumab}

Trastuzumab (Herceptin ${ }^{\circledR}$ ) is a humanized IgG1-class monoclonal EGFR antibody inhibitor that prevents erbB hetero and homodimerization by binding to the extracellular domain of EGFR [22]. Trastuzumab therapy has shown to increase patient survival rate in HER2-overexpressed breast cancers, although the precise mechanism of action remains unclear [4,23-27]. As a monotherapeutic agent trastuzumab shows a $15 \%-26 \%$ response rate in HER2-positive breast cancer, with a median duration of 9 months [22]. In clinical benefit rates measuring a stable disease of 6 months or greater in combination with the overall response rate, trastuzumab shows a $36 \%-48 \%$ benefit in HER2-positive patients [22]. When combined with chemotherapy, trastuzumab shows even greater increased overall patient survival, progression-free survival, and higher response rates than as a single treatment alone [27-32]. It is of note, however, that many HER2-overexpressing patients do not respond to trastuzumab treatment alone, and almost all patients develop resistance over time. It has been suggested that a better understanding of molecular mechanisms underlying primary or acquired resistance to trastuzumab is essential for exploring alternative therapeutic avenues. The administration of tyrosine kinase inhibitors either alone or in combination with trastuzumab or antibody-drug conjugates have been suggested as viable alternatives [33].

\subsection{Pertuzumab}

Pertuzumab (Perjeta ${ }^{\circledR}$ ) is a recombinant humanized monoclonal antibody that exhibits a different extracellular binding specificity than trastuzumab, providing a more comprehensive signal blockade than trastuzumab treatment alone. It was granted accelerated approval by the U.S. Food and Drug Administration based on its phase II pathologic complete response rate $(\mathrm{pCR})$ in neoadjuvant treatments of HER2-positive early-stage, inflammatory, and locally advanced breast cancer with trastuzumab and docetaxel [34]. Both arms of a phase IIa trial investigating the first-line treatment of pertuzumab in combination with trastuzumab, capacitabine and cisplatin in HER2-positive advanced gastric cancer found the drugs to be well tolerated, with a partial response achieved by $86 \%$ (arm A) and 55\% (arm B) of patients [35]. In a double-blind, randomized phase III trial comparing the safety and efficacy of pertuzumab with trastuzumab and docetaxel, the median progression-free survival was 18.5 months; while the overall survival and objective response rate $(80.2 \%)$ was higher than the observed placebo 
group, leading the European Medicines Agency to also approve pertuzumab for treating HER2-positive breast cancer [36].

\section{Small Molecules as HER2 Kinase Inhibitors}

The human genome encodes hundreds of protein kinases that share a conserved catalytic domain in sequence and structure, but are very different in catalysis regulation [37]. Small molecule tyrosine kinase inhibitors compete with ATP at the cytoplasmic catalytic kinase domain to prevent tyrosine phosphorylation and signaling events downstream of ligand binding. Due to the conserved kinase structure, many small molecule targeted therapies exhibit a degree of promiscuity and bind to multiple kinases. Thus, maintaining a high selectivity profile is very important in developing new inhibitors. Protein crystal structures and computational molecular modeling and docking studies have been invaluable in the kinase drug design process. Simulations used to identify key structures and restrictions in the binding pockets allow novel compounds to be screened efficiently. These compounds can exhibit high affinity relationships with their therapeutic targets and thus increase the overall productivity of the hit to lead and optimization strategies used in drug development. The kinase domain of the four members of the ERB family of receptors shows a high degree of homology $(59 \%-81 \%)$ with greater sequence divergence in the $\mathrm{C}$-terminal residues $(11 \%-25 \%$ identity). HER2 appears to be the preferred binding partner for the formation of heterodimers with other members of the ERB family. The HER2/EGFR heterodimer shows enhanced potency when compared to the EGFR homodimer [10]. The HER2 kinase is intrinsically autoinhibited in the cell unlike other receptor tyrosine kinases that require phosphorylation of the activation loop. Recent research on the kinase domains of the dimers has revealed an allosteric mechanism of activation of EGFR and HER4 via dimer formation [38-41].

\subsection{HER2 Tyrosine Kinase Inhibitors}

\subsubsection{Lapatinib}

Lapatinib (Tykerb/Tyverb ${ }^{\circledR}$ ) (Figure 1) is an orally active dual EGFR/HER2 tyrosine kinase inhibitor. The development of lapatinib was determined in part by the preclinical evaluations favoring synergistic cell proliferation inhibition using EGFR targeted therapies alongside HER2 inhibitors [11,42]. Lapatinib demonstrated a greater apoptotic response than single agent inhibition alone in SKBR-3 and BT-474 HER2 overexpressing cell lines [43].

In a recent randomized phase III trial evaluating the efficacy of dual targeted trastuzumab and lapatinib treatments in early-stage HER2 positive breast cancer, the North American Breast Cancer Group (NABCG) and the Breast International Group (BIG) found no significant statistical advantage in invasive disease free survival over single agent trastuzumab treatment alone in an 8000 patient population size $[25,44]$. The Adjuvant Lapatinib and/or Trastuzumab Treatment Optimisation (ALTTO) trial compared patients receiving a combination of three lapatinib-containing regimens with trastuzumab over the course of a year. Only $6.9 \%$ of patients with disease free survival using lapatinib and trastuzumab dual therapies were observed over a 4.5-year median follow up. The study, while groundbreaking in sheer population size and diversity, was somewhat disappointing in the potential of lapatinib as a combinatorial therapeutic agent with trastuzumab. Nevertheless, the data will provide 
insight into a more comprehensive understanding of cooperative drug inhibition and enable better treatment options for current and future HER2-positive patients.

Figure 1. Structures of the HER2 tyrosine kinase inhibitors.

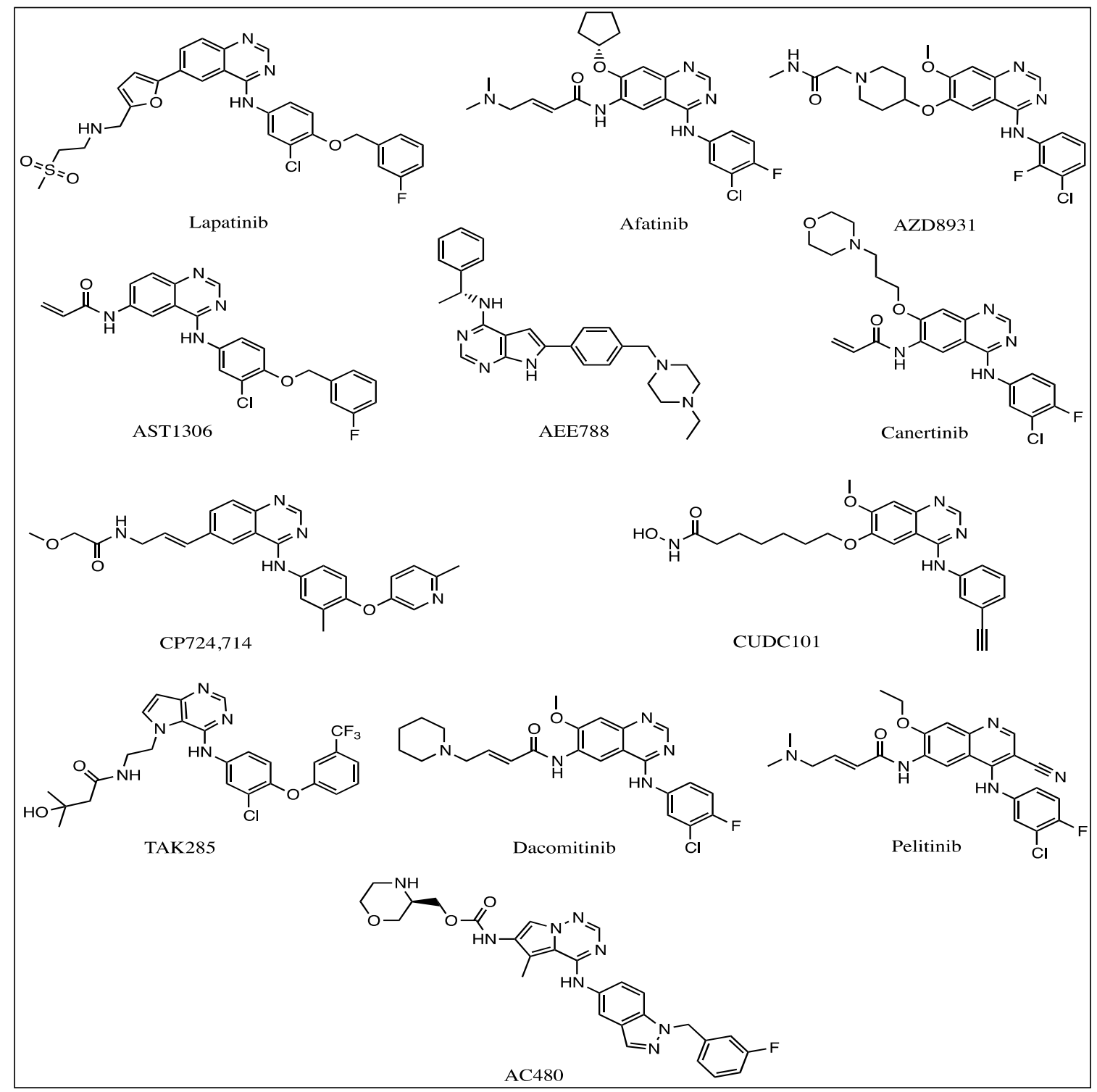

\subsubsection{Afatinib}

Afatinib (Gilotrif/Giotrif ${ }^{\circledR}$ ) is a highly selective orally bioavailable irreversible pan inhibitor approved for use in treating metastatic non-small cell lung carcinoma (NSCLC). While its antitumoral activity is well documented in NSCLC, its activity targeting metastatic breast cancer is still being evaluated. Afatinib has an in vitro $\mathrm{IC}_{50}$ of $0.5 \mathrm{nM}$ in EGFR and $14 \mathrm{nM}$ in HER2 and showed promising activity in preclinical studies using EGFR and HER2-overexpressing trastuzumab-resistant cell lines (SUM 190-PT) and HER2-negative cells (SUM 149-PT) [45-47]. It also demonstrated encouraging results in multiple phase I clinical trials when used as a monotherapy and in combination with chemotherapy though its toxicity profile remains high $[46,48,49]$. 


\subsubsection{AZD8931}

AZD8931 is an orally active reversible equipotent inhibitor of EGFR, HER2, and HER3. It has shown to be more potent than lapatinib and gefitinib in NSCLCs and also exhibits high selectivity for HER kinases against those outside the HER family $[43,50]$. In a study investigating the antitumor activity of AZD8931 in preclinical models of EGFR-overexpressed and HER2 non-amplified breast cancer cell lines (SUM 149 and FC-IBC-02, respectively), significant suppression of cell growth and induced apoptosis was observed in combination with paclitaxel therapy [51]. A two-part phase I trial assessing the safety and tolerability of single agent AZD8931 in patients with advanced solid tumors and as a combinatorial therapy with paclitaxel in female patients expressing advanced metastatic breast cancer showed no dose-limiting toxicities in either case [52]. AZD8931 was highly absorbed (median $t_{\max }=1-3 \mathrm{~h}$ ) in another study, displaying an elimination half-life of approximately 11 hours with moderate to high clearance; while the maximum tolerated dose from a 21-day evaluation was $240 \mathrm{mg}$ [53]. However, more data must be obtained to confirm an appropriate maximum tolerated dose for use in chronic treatment.

\subsection{Emerging HER2 Tyrosine Kinase Inhibitors}

\subsubsection{AST-1306}

AST-1306 is a selective orally active irreversible EGFR and HER2 inhibitor. Studies demonstrated weakly inhibiting EGFR tumor suppression activity in SK-OV-3 cell lines when HER2 knockdown occurred in vivo, and potent tumor suppression was exhibited in HER2-overexpressing adenocarcinoma xenograft and FVB-2/N(neu) transgenic breast cancer mouse models [54]. A phase I dose-escalation study evaluating the safety, tolerability, pharmacokinetics, and anti-tumor effects of AST-1306 found it to be rapidly absorbed with moderate to high clearance; and a pharmacokinetic concentration consistent over the evaluated dose range [55]. Further data is needed, but a recommended dosage of a $1000 \mathrm{mg}$ three times daily is suggested for additional phase II trials [55].

\subsubsection{AEE-788}

AEE-788 is a dual specific reversible EGFR and HER2 kinase inhibitor. A study investigating the effects of AEE-788 on EGFR and HER2 in glioblastoma cells (LN-18 and LN-229 cell lines, respectively) expressing varying co-expression levels followed by experimental radiotherapy showed HER2-overexpressing sensitivity, while demonstrating induced inhibition on previously resistant EGFR-overexpressing cells [56]. AEE-788 also showed EGFR/HER2 heterodimerization inhibition in overexpressing LN-18 cells, suggesting HER2 inhibition in EGFR-overexpressing cells may provide a therapeutic strategy in EGFR resistant cells. The antitumoral efficacy of AEE-788 in combination with tamoxifen or letrozole showed enhanced anti-proliferative effects in estrogen receptor positive $(\mathrm{ER}+)$ cell lines (MCF-7 2A, ZR75.1 A3 and BT474 A3) [57]. However, when used as a single agent and in combinatorial endocrine therapy treatment, an elevation in progesterone receptor (PGR) and trefoil factor 1 (TFF1) gene expression was observed in BT474 A3 cells [57]. In combination with letrozole, AEE-788 was also found to produce significant inhibition compared to tamoxifen dual therapy in ZR75.1 
A3 xenograft, suggesting AEE-788 and letrozole may provide increased tumor inhibition in breast cancer tumor cells when compared against single agent use or in combination with tamoxifen alone.

\subsubsection{CI-1033 (Canertinib)}

CI-1033 is a highly selective irreversible orally bioactive EGFR, HER2, and HER4 tyrosine kinase inhibitor. CI-1033 was evaluated for its ability to inhibit tumor formation in esophageal squamous cell carcinoma (TT, TE2, TE6, TE10 cell lines) in vitro and in vivo with EGFR and HER2 overexpression in all four cell lines [58]. It was found to silence MAPK and Akt signaling pathways along with the suppression of kinase phosphorylation. As a single agent treatment in a randomized phase II trial evaluating patients with pretreated metastatic breast cancer, CI-1033 showed no meaningful clinical activity. However, antitumor activity was observed in one arm of the study, though doses higher than $50 \mathrm{mg}$ were generally not well tolerated, and unacceptable toxicity levels were exhibited at the highest dose [59].

\subsubsection{CP-724714}

CP-724714 is a reversible orally active selective HER2 kinase inhibitor. Early stage pharmacologic characterization studies showed CP-724714 to be a potent autophosphorylation inhibitor and G1 cell cycle blocking inducer in HER2-overexpressing BT474 human breast carcinoma cells [60]. It also demonstrated potent inhibition of HER2-overexpressed tumor growth in athymic mice with no signs of adverse effects. A phase I dose-escalating study evaluating the safety, tolerability, and pharmaco-kinetic effects on patients with advanced malignant solid HER2 expressing tumors found a maximum tolerated dose of $250 \mathrm{mg}$ three times daily with a dose-limiting toxicity including elevated alanine aminotransferase, thrombocytopenia, and hyperbilirubinemia as well as pulmonary embolus [61]. It was proposed that CP-724714 induced inhibition of hepatic efflux transporters that contributed to an accumulation of drug and bile levels in the liver leading to hepatobiliary cholestasis [61]. CP-724714 has since been discontinued in clinical development.

\subsubsection{CUDC-101}

The discovery of CUDC-101, an irreversible HDAC, EGFR, and HER2 inhibitor, resulted from the incorporation of histone deacetylase (HDAC) functionality into the EGFR and HER2 inhibitor pharmacophore. It showed higher potency than erlotinib and lapatinib in most of the tumor lines tested, with an EGFR and HER2 in vitro kinase IC 50 of 2.4 and $15.7 \mathrm{nM}$ respectively [62]. Due to HDAC action, CUDC-101 was shown to reduce regulation in multiple proliferative signaling pathways such as MET, Akt, and HER3, allowing it to overcome some limitations brought about by conventional HER signaling inhibition [63]. A phase I trial investigating the maximum tolerated dose in patients receiving chemoradiation in untreated locally advanced squamous cell head and neck carcinomas found a maximum dose of $275 \mathrm{mg} / \mathrm{m}^{2}$ with a dose limiting toxicity of acute renal failure derived from elevated creatinine levels in one patient [64]. 


\subsubsection{TAK-285}

TAK-285 is an orally active irreversible potent dual EGFR/HER2 inhibitor exhibiting an IC $_{50}$ of 2.5 and $0.98 \mathrm{nM}$, respectively, and a cell growth inhibitory activity (GI50) of $2.0 \mathrm{nM}$ in subcutaneous mouse BT-474 cells. It also showed potent tumor regression in both EGFR-overexpressing (4-1ST) and HER2-overexpressing (CAL27) tumor xenograft mouse models with $50 \mathrm{mg} / \mathrm{kg}$ and $100 \mathrm{mg} / \mathrm{kg}$ oral doses [65]. Its therapeutic potential in HER2-overexpressing brain metastasis was verified by in vivo microdialysis evaluations detecting unbound levels of TAK-285 in the extracellular space in the brain for up to 24-48 h after administration [66]. The toxicity profile and pharmacokinetic studies in a phase I trial found rapid absorption after oral dosing with increased plasma exposure in a dose-dependent fashion. The dose limiting toxicities were noted as a grade 3 increase in aminotransferases as well as grade 3 appetite suppression in a $400 \mathrm{mg}$ twice daily regimen [67].

\subsubsection{AC-480 (BMS-599626)}

AC-480 is an orally bioavailable reversible EGFR, HER2, and HER4 inhibitor. It showed an accumulation of cells in the G1 phase and demonstrated significant enhancement of radiosensitivity in NH-5 cells, as well as phosphorylation inhibition of EGFR, HER2, Rb, Akt, MAPK, CDK1/2/6, and $\mathrm{Ku} 70$ proteins [68]. In a phase I trial in patients with advanced solid tumors, a maximum tolerated dose of $600 \mathrm{mg}$ /day was recommended, with a dose-limiting toxicity of grade 3 elevated hepatic transaminases and QTc interval prolongation reported in $660 \mathrm{mg} /$ day doses [69]. AC-480 was well tolerated in the phase I study with 11 patients $(n=45)$ exhibiting a stable disease condition of 4 months or greater. It is also of note that AC-480 exhibited increased cell line-dependent synergistic or additive apoptosis in head and neck squamous cell carcinomas when used as a co-inhibitor with the insulin-like growth factor-1 receptor 1 (IGF1R) inhibitor, BMS-754807 [69].

\subsubsection{PF299804, PF299 (Dacomitinib)}

Dacomitinib is an orally active irreversible EGFR, HER2, and HER4 inhibitor. A phase I dose-escalation study in patients with advanced NSCLC solid tumors found dacomitinib to be well tolerated, exhibiting a maximum tolerated dose of $45 \mathrm{mg} /$ day and a dose-limiting toxicity of stomatitis and skin toxicities [70]. Patients previously treated with erlotinib or gefitinib showed the most encouraging signs of antitumor activity. Dacomitinib also demonstrated inhibition of HER2-amplified trastuzumab and lapatinib resistant breast cancer cell lines in vitro; exerting its antiproliferative effects through a G0- G1 combined cell cycle arrest and inducing apoptosis [71]. A phase II trial investigating the effects of dacomitinib in patients with NSCLC who previously received failed erlotinib and chemotherapy treatments $(n=66)$ showed acceptable tolerability and limited objective response rates in adenocarcinoma $(5 \%, n=50)$ and nonademocarcinoma $(6 \%, n=16)$ patients [72].

\subsubsection{EKB-569 (Perlitinib)}

Perlitinib is an orally active irreversible selective dual EGFR/HER2 inhibitor. A phase I dose-escalation trial investigating the administration of pelitinib in patients with advanced solid tumors found a maximum tolerated once daily dose of $75 \mathrm{mg}$ /day, with a low toxicity profile showing grade 3 diarrhea 
as the major dose-limiting toxic effects [73]. No significant antitumor responses were observed, however one NSCLC patient and another cutaneous squamous cell carcinoma patient showed stable disease for 33 and 24 weeks, respectively (Table 2).

Table 2. Specificity profiles of HER2 kinase inhibitors.

\begin{tabular}{cccccc}
\hline Inhibitor & $\begin{array}{c}\text { EGFR IC } \\
\text { (nM) }\end{array}$ & $\begin{array}{c}\text { HER2 IC 50 } \\
(\mathbf{n M )}\end{array}$ & $\begin{array}{c}\text { HER3 IC 50 } \\
(\mathbf{n M )}\end{array}$ & $\begin{array}{c}\text { HER4 IC }_{\text {50 }} \\
(\mathbf{n M})\end{array}$ & Characteristics \\
\hline Lapatinib [74] & 10.2 & 9.8 & - & 367 & Reversible \\
Afatinib [75] & 0.5 & 14 & - & - & Irreversible \\
AZD8931 [50] & 4 & 3 & 4 & - & Irreversible \\
AST-1306 [54] & 0.5 & 3.0 & - & 0.8 & Reversible \\
AEE-788 [76] & 2 & 6 & - & 160 & Reversible \\
CI-1033 (Canertinib) [77] & 1.5 & 9.0 & - & - & Irreversible \\
CP724,714 [60] & - & 9.8 & - & - & Reversible \\
CUDC-101 [78] & 2.4 & 15.7 & - & - & Irreversible \\
TAK-285 [79] & 24 & 36 & - & 260 & Irreversible \\
AC-480 (BMS-599626) [80] & 22 & 32 & - & 190 & Reversible \\
PF299804 PF299 (Dacomitinib) [75] & 6.0 & 45.7 & - & 73.7 & Irreversible \\
EKB-569 (Pelitinib) [73] & 38.5 & 1.26 & - & - & Irreversible \\
\hline
\end{tabular}

Figure 2. Structures of new HER2 kinase inhibitors.

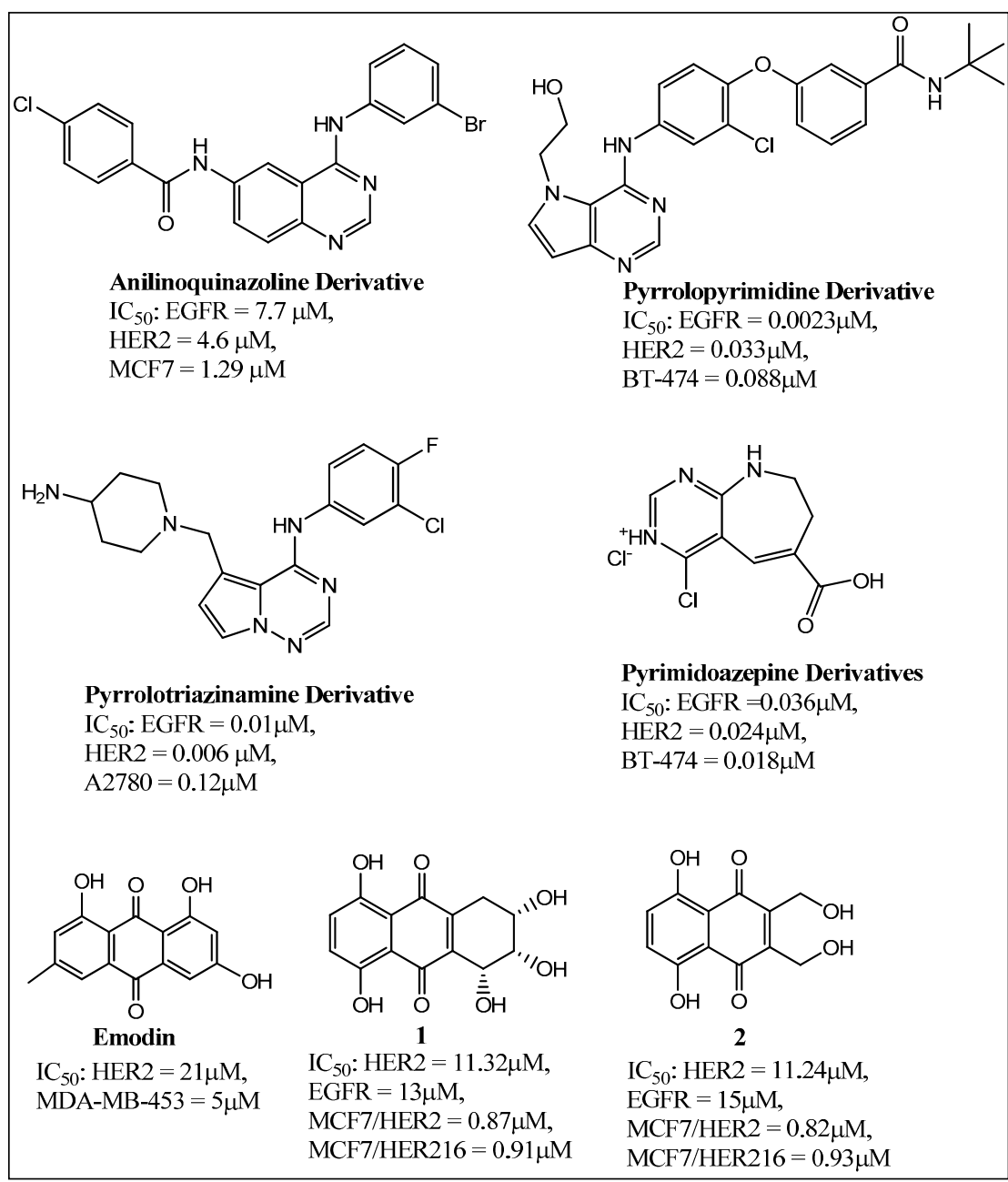




\subsection{Ongoing Search for New Inhibitors}

Several classes of organic molecules are being explored for their potential to inhibit EGFR and HER2 tyrosine kinases. Among them several nitrogen heterocycle-containing scaffolds such as pyrrolotriazinamines [81], anilinoquinazolines [82,83], pyrimidoazepines [79], pyrrolopyrimidines [84,85], and purines [86] have been found to inhibit EGFR and/or HER2 kinase with significantly high potency. The structures of some of the most potent inhibitors are given in Figure 1. Other than nitrogen heterocycles as tyrosine kinase inhibitors, anthraquinones such as emodin [87] and quinone derivatives analyzed in our laboratory [88] have shown the potential to inhibit the growth of breast cancer cells through inhibition of the tyrosine kinases belonging to the ERB family of receptors. Emodin is known to be a pan kinase inhibitor. The ability of the compounds to inhibit HER2 kinase activity directly was tested by using the ADP-Glo in vitro kinase assay kit from Promega. The quinones 1 and 2 (Figure 2) inhibited EGFR and HER2 kinases with equal but low micromolar potency. But these same quinones showed a much higher potency in the inhibition of breast tumor cells expressing HER2 or the trastuzumab resistant HER2 oncogenic isoform, HER2 $\Delta 16$ (The IC50 of the effective compounds was measured by treating each of the cell lines with different drug concentrations for $48 \mathrm{~h}$ followed by the CellTiter-Glo Assay to detect cell viability).

\section{Conclusions}

The development of resistance to monoclonal antibody trastuzumab within a year of treatment and the presence of truncated forms of HER2 (p95 ${ }^{\text {HER2 }}$ and HER2 $\Delta 16$ ) has led the shift in focus of research to the targeting of the kinase domain for the development of therapeutics. Even though lapatinib, a dual inhibitor of EGFR and HER2 kinases showed great promise in phase I and phase II trials, a subsequent phase III trial found no significant advantage over the single agent treatment trastuzumab in disease free survival. Many other small molecule inhibitors of the kinases are presently undergoing phase trials. While some have shown toxicity leading to the discontinuation of their phase trials, other agents have moved on to the phase III trials. The therapeutic potential of these new agents is still unproven. The need remains for a therapeutic agent that can have a long term impact on the treatment of breast cancer and to ensure disease free survival.

\section{Acknowledgments}

The work was funded by the Department of Defense Award W81XWH-11-1-0105. Richard Schroeder was supported by funds from the Louisiana Cancer Research Consortium. The contents are solely the responsibility of the authors and do not represent the official views of NIH.

\section{Conflicts of Interest}

The authors declare no conflict of interest. 


\section{References}

1. Slamon, D.J.; Godolphin, W.; Jones, L.A.; Holt, J.A.; Wong, S.G.; Keith, D.E.; Levin, W.J.; Stuart, S.G.; Udove, J.; Ullrich, A.; et al. Studies of the HER-2/neu proto-oncogene in human breast and ovarian cancer. Science 1989, 244, 707-712.

2. Bacus, S.S.; Zelnick, C.R.; Plowman, G.; Yarden, Y. Expression of the erbb-2 family of growth factor receptors and their ligands in breast cancers. Implication for tumor biology and clinical behavior. Am. J. Clin. Pathol. 1994, 102, S13-S24.

3. Slamon, D.J.; Clark, G.M.; Wong, S.G.; Levin, W.J.; Ullrich, A.; McGuire, W.L. Human breast cancer: Correlation of relapse and survival with amplification of the HER-2/neu oncogene. Science 1987, 235, 177-182.

4. Pegram, M.D.; Lipton, A.; Hayes, D.F.; Weber, B.L.; Baselga, J.M.; Tripathy, D.; Baly, D.; Baughman, S.A.; Twaddell, T.; Glaspy, J.A.; et al. Phase II study of receptor-enhanced chemosensitivity using recombinant humanized anti-p185HER2/neu monoclonal antibody plus cisplatin in patients with HER2/neu-overexpressing metastatic breast cancer refractory to chemotherapy treatment. J. Clin. Oncol. 1998, 16, 2659-2671.

5. Arteaga, C.L. Progress in breast cancer: Overview. Clin. Cancer Res. 2013, 19, 6353-6359.

6. Zhang, X.H.; Giuliano, M.; Trivedi, M.V.; Schiff, R.; Osborne, C.K. Metastasis dormancy in estrogen receptor-positive breast cancer. Clin. Cancer Res. 2013, 19, 6389-6397.

7. Yarden, Y.; Sliwkowski, M.X. Untangling the erbb signalling network. Nat. Rev. Mol. Cell Biol. 2001, 2, 127-137.

8. Hynes, N.E.; Lane, H.A. Erbb receptors and cancer: The complexity of targeted inhibitors. Nat. Rev. Cancer 2005, 5, 341-354.

9. Olayioye, M.A.; Graus-Porta, D.; Beerli, R.R.; Rohrer, J.; Gay, B.; Hynes, N.E. Erbb-1 and erbb-2 acquire distinct signaling properties dependent upon their dimerization partner. Mol. Cell. Biol. 1998, 18, 5042-5051.

10. Lenferink, A.E.; Pinkas-Kramarski, R.; van de Poll, M.L.; van Vugt, M.J.; Klapper, L.N.; Tzahar, E.; Waterman, H.; Sela, M.; van Zoelen, E.J.; Yarden, Y. Differential endocytic routing of homo- and hetero-dimeric erbb tyrosine kinases confers signaling superiority to receptor heterodimers. EMBO J. 1998, 17, 3385-3397.

11. Tural, D.; Akar, E.; Mutlu, H.; Kilickap, S. P95 HER2 fragments and breast cancer outcome. Expert Rev. Anticancer Ther. 2014, 1-8.

12. Arribas, J.; Baselga, J.; Pedersen, K.; Parra-Palau, J.L. P95HER2 and breast cancer. Cancer Res. 2011, 71, 1515-1519.

13. Hojjat-Farsangi, M. Small-molecule inhibitors of the receptor tyrosine kinases: Promising tools for targeted cancer therapies. Int. J. Mol. Sci. 2014, 15, 13768-13801.

14. Norman, P. Inducible tyrosine kinase inhibitors: A review of the patent literature (2010-2013). Expert Opin. Ther. Pat. 2014, 24, 979-991.

15. Roskoski, R., Jr. Erbb/HER protein-tyrosine kinases: Structures and small molecule inhibitors. Pharmacol. Res. 2014, 87C, 42-59.

16. Cui, J.J. Targeting receptor tyrosine kinase met in cancer: Small molecule inhibitors and clinical progress. J. Med. Chem. 2014, 57, 4427-4453. 
17. Anandappa, G.; Turner, N.C. Targeting receptor tyrosine kinases in HER2-negative breast cancer. Curr. Opin. Oncol. 2013, 25, 594-601.

18. Warnault, P.; Yasri, A.; Coisy-Quivy, M.; Cheve, G.; Bories, C.; Fauvel, B.; Benhida, R. Recent advances in drug design of epidermal growth factor receptor inhibitors. Curr. Med. Chem. 2013, 20, 2043-2067.

19. Ocana, A.; Pandiella, A. Targeting HER receptors in cancer. Curr. Pharm. Des. 2013, 19, 808-817.

20. Arteaga, C.L.; Sliwkowski, M.X.; Osborne, C.K.; Perez, E.A.; Puglisi, F.; Gianni, L. Treatment of HER2-positive breast cancer: Current status and future perspectives. Nat. Rev. Clin. Oncol. 2011, 9, 16-32.

21. Saini, K.S.; Azim, H.A., Jr.; Metzger-Filho, O.; Loi, S.; Sotiriou, C.; de Azambuja, E.; Piccart, M. Beyond trastuzumab: New treatment options for HER2-positive breast cancer. Breast 2011, 20 (Suppl. 3), S20-S27.

22. Nielsen, D.L.; Kümler, I.; Palshof, J.A.; Andersson, M. Efficacy of HER2-targeted therapy in metastatic breast cancer. Monoclonal antibodies and tyrosine kinase inhibitors. Breast 2013, 22, 1-12.

23. Baselga, J.; Tripathy, D.; Mendelsohn, J.; Baughman, S.; Benz, C.C.; Dantis, L.; Sklarin, N.T.; Seidman, A.D.; Hudis, C.A.; Moore, J.; et al. Phase II study of weekly intravenous recombinant humanized anti-p185HER2 monoclonal antibody in patients with HER2/neu-overexpressing metastatic breast cancer. J. Clin. Oncol. 1996, 14, 737-744.

24. Cobleigh, M.A.; Vogel, C.L.; Tripathy, D.; Robert, N.J.; Scholl, S.; Fehrenbacher, L.; Wolter, J.M.; Paton, V.; Shak, S.; Lieberman, G.; et al. Multinational study of the efficacy and safety of humanized anti-HER 2 monoclonal antibody in women who have HER2-overexpressing metastatic breast cancer that has progressed after chemotherapy for metastatic disease. J. Clin. Oncol. 1999, 17, 2639-2648.

25. Piccart-Gebhart, M.J.; Procter, M.; Leyland-Jones, B.; Goldhirsch, A.; Untch, M.; Smith, I.; Gianni, L.; Baselga, J.; Bell, R.; Jackisch, C.; et al. Trastuzumab after adjuvant chemotherapy in HER2-positive breast cancer. N. Engl. J. Med. 2005, 353, 1659-1672.

26. Romond, E.H.; Perez, E.A.; Bryant, J.; Suman, V.J.; Geyer, C.E., Jr.; Davidson, N.E.; Tan-Chiu, E.; Martino, S.; Paik, S.; Kaufman, P.A.; et al. Trastuzumab plus adjuvant chemotherapy for operable HER2-positive breast cancer. N. Engl. J. Med. 2005, 353, 1673-1684.

27. Slamon, D.J.; Leyland-Jones, B.; Shak, S.; Fuchs, H.; Paton, V.; Bajamonde, A.; Fleming, T.; Eiermann, W.; Wolter, J.; Pegram, M.; et al. Use of chemotherapy plus a monoclonal antibody against HER2 for metastatic breast cancer that overexpresses HER2. N. Engl. J. Med. 2001, 344, 783-792.

28. Esteva, F.J.; Valero, V.; Booser, D.; Guerra, L.T.; Murray, J.L.; Pusztai, L.; Cristofanilli, M.; Arun, B.; Esmaeli, B.; Fritsche, H.A.; et al. Phase II study of weekly docetaxel and trastuzumab for patients with HER-2-overexpressing metastatic breast cancer. J. Clin. Oncol. 2002, 20, 1800-1808.

29. O’Shaughnessy, J.A.; Vukelja, S.; Marsland, T.; Kimmel, G.; Ratnam, S.; Pippen, J.E. Phase II study of trastuzumab plus gemcitabine in chemotherapy-pretreated patients with metastatic breast cancer. Clin. Breast Cancer 2004, 5, 142-147.

30. Pegram, M.D.; Konecny, G.E.; O’Callaghan, C.; Beryt, M.; Pietras, R.; Slamon, D.J. Rational combinations of trastuzumab with chemotherapeutic drugs used in the treatment of breast cancer. J. Natl. Cancer Inst. 2004, 96, 739-749. 
31. Seidman, A.D.; Fornier, M.N.; Esteva, F.J.; Tan, L.; Kaptain, S.; Bach, A.; Panageas, K.S.; Arroyo, C.; Valero, V.; Currie, V.; et al. Weekly trastuzumab and paclitaxel therapy for metastatic breast cancer with analysis of efficacy by HER2 immunophenotype and gene amplification. J. Clin. Oncol. 2001, 19, 2587-2595.

32. Baselga, J.; Albanell, J. Mechanism of action of anti-HER2 monoclonal antibodies. Ann. Oncol. 2001, 12, S35-S41.

33. Dokmanovic, M.; Wu, J.W. Mechanisms of trastuzumab resistance and opportunities to overcome therapeutic resistance. J. Mol. Biomark. Diagn. 2013, 4, doi:10.4172/2155-9929.1000e116.

34. Abraham, J.; Stenger, M. Pertuzumab in neoadjuvant treatment of HER2-positive early breast cancer. J. Community Support. Oncol. 2014, 12, 84-86.

35. Kang, Y.K.; Rha, S.Y.; Tassone, P.; Barriuso, J.; Yu, R.; Szado, T.; Garg, A.; Bang, Y.J. A phase IIa dose-finding and safety study of first-line pertuzumab in combination with trastuzumab, capecitabine and cisplatin in patients with HER2-positive advanced gastric cancer. Br. J. Cancer 2014, 111, 660-666.

36. Boix-Perales, H.; Borregaard, J.; Jensen, K.B.; Ersboll, J.; Galluzzo, S.; Giuliani, R.; Ciceroni, C.; Melchiorri, D.; Salmonson, T.; Bergh, J.; et al. The european medicines agency review of pertuzumab for the treatment of adult patients with HER2-positive metastatic or locally recurrent unresectable breast cancer: Summary of the scientific assessment of the committee for medicinal products for human use. Oncologist 2014, 19, 766-773.

37. Noble, M.E.; Endicott, J.A.; Johnson, L.N. Protein kinase inhibitors: Insights into drug design from structure. Science 2004, 303, 1800-1805.

38. Aertgeerts, K.; Skene, R.; Yano, J.; Sang, B.C.; Zou, H.; Snell, G.; Jennings, A.; Iwamoto, K.; Habuka, N.; Hirokawa, A.; et al. Structural analysis of the mechanism of inhibition and allosteric activation of the kinase domain of HER2 protein. J. Biol. Chem. 2011, 286, 18756-18765.

39. Qiu, C.; Tarrant, M.K.; Choi, S.H.; Sathyamurthy, A.; Bose, R.; Banjade, S.; Pal, A.; Bornmann, W.G.; Lemmon, M.A.; Cole, P.A.; et al. Mechanism of activation and inhibition of the HER4/erbb4 kinase. Structure 2008, 16, 460-467.

40. Zhang, X.; Gureasko, J.; Shen, K.; Cole, P.A.; Kuriyan, J. An allosteric mechanism for activation of the kinase domain of epidermal growth factor receptor. Cell 2006, 125, 1137-1149.

41. Zhang, X.; Pickin, K.A.; Bose, R.; Jura, N.; Cole, P.A.; Kuriyan, J. Inhibition of the egf receptor by binding of mig6 to an activating kinase domain interface. Nature 2007, 450, 741-744.

42. Zhou, Y.; Li, S.; Hu, Y.P.; Wang, J.; Hauser, J.; Conway, A.N.; Vinci, M.A.; Humphrey, L.; Zborowska, E.; Willson, J.K.; et al. Blockade of EGFR and erbB2 by the novel dual EGFR and erbB2 tyrosine kinase inhibitor GW572016 sensitizes human colon carcinoma geo cells to apoptosis. Cancer Res. 2006, 66, 404-411.

43. Moulder, S.L.; Yakes, F.M.; Muthuswamy, S.K.; Bianco, R.; Simpson, J.F.; Arteaga, C.L. Epidermal growth factor receptor (HER1) tyrosine kinase inhibitor ZD1839 (Iressa) inhibits HER2/neu (erbB2)-overexpressing breast cancer cells in vitro and in vivo. Cancer Res. 2001, 61, 8887-8895.

44. Piccart-Gebhart, M.J.; Holmes, A.P.; Baselga, J.; Azambuja, E.D.; Dueck, A.C.; Viale, G.; Zujewski, J.A.; Goldhirsch, A.; Santillana, S.; Pritchard, K.I.; et al. First results from the phase III ALTTO trial (BIG 2-06; NCCTG [alliance] N063D) comparing one year of anti-HER2 therapy with 
lapatinib alone $(\mathrm{L})$, trastuzumab alone $(\mathrm{T})$, their sequence $(\mathrm{T} \rightarrow \mathrm{L})$, or their combination $(\mathrm{T}+\mathrm{L})$ in the adjuvant treatment of HER2-positive early breast cancer (EBC). J. Clin. Oncol. 2014, 32 (Suppl.), 5s, Abstract LBA4.

45. Geuna, E.; Montemurro, F.; Aglietta, M.; Valabrega, G. Potential of afatinib in the treatment of patients with HER2-positive breast cancer. Breast Cancer (Dove Med. Press) 2012, 4, 131-137.

46. Li, D.; Ambrogio, L.; Shimamura, T.; Kubo, S.; Takahashi, M.; Chirieac, L.R.; Padera, R.F.; Shapiro, G.I.; Baum, A.; Himmelsbach, F.; et al. Bibw2992, an irreversible egfr/HER2 inhibitor highly effective in preclinical lung cancer models. Oncogene 2008, 27, 4702-4711.

47. Katakami, N.; Atagi, S.; Goto, K.; Hida, T.; Horai, T.; Inoue, A.; Ichinose, Y.; Koboyashi, K.; Takeda, K.; Kiura, K.; et al. Lux-lung 4: A phase II trial of afatinib in patients with advanced non-small-cell lung cancer who progressed during prior treatment with erlotinib, gefitinib, or both. J. Clin. Oncol. 2013, 31, 3335-3341.

48. Eskens, F.A.; Mom, C.H.; Planting, A.S.; Gietema, J.A.; Amelsberg, A.; Huisman, H.; van Doorn, L.; Burger, H.; Stopfer, P.; Verweij, J.; et al. A phase I dose escalation study of bibw 2992, an irreversible dual inhibitor of epidermal growth factor receptor 1 (egfr) and 2 (HER2) tyrosine kinase in a 2-week on, 2-week off schedule in patients with advanced solid tumours. Br. J. Cancer 2008, 98, 80-85.

49. Yap, T.A.; Vidal, L.; Adam, J.; Stephens, P.; Spicer, J.; Shaw, H.; Ang, J.; Temple, G.; Bell, S.; Shahidi, M.; et al. Phase I trial of the irreversible egfr and HER2 kinase inhibitor bibw 2992 in patients with advanced solid tumors. J. Clin. Oncol. 2010, 28, 3965-3972.

50. Barlaam, B.; Anderton, J.; Ballard, P.; Bradbury, R.H.; Hennequin, L.F.; Hickinson, D.M.; Kettle, J.G.; Kirk, G.; Klinowska, T.; Lambert-van der Brempt, C.; et al. Discovery of azd8931, an equipotent, reversible inhibitor of signaling by egfr, HER2, and HER3 receptors. ACS Med. Chem. Lett. 2013, 4, 742-746.

51. Mu, Z.; Klinowska, T.; Dong, X.; Foster, E.; Womack, C.; Fernandez, S.V.; Cristofanilli, M. AZD8931, an equipotent, reversible inhibitor of signaling by epidermal growth factor receptor (EGFR), HER2, and HER3: Preclinical activity in HER2 non-amplified inflammatory breast cancer models. J. Exp. Clin. Cancer Res. 2014, 33, 47.

52. Kurata, T.; Tsurutani, J.; Fujisaka, Y.; Okamoto, W.; Hayashi, H.; Kawakami, H.; Shin, E.; Hayashi, N.; Nakagawa, K. Inhibition of egfr, HER2 and HER3 signaling with azd8931 alone and in combination with paclitaxel: Phase I study in japanese patients with advanced solid malignancies and advanced breast cancer. Investig. New Drugs 2014, doi:10.1007/s10637-014-0112-7.

53. Tjulandin, S.; Moiseyenko, V.; Semiglazov, V.; Manikhas, G.; Learoyd, M.; Saunders, A.; Stuart, M.; Keilholz, U. Phase I, dose-finding study of AZD8931, an inhibitor of EGFR (erbB1), HER2 (erbB2) and HER3 (erbB3) signaling, in patients with advanced solid tumors. Investig. New Drugs 2014, $32,145-153$.

54. Xie, H.; Lin, L.; Tong, L.; Jiang, Y.; Zheng, M.; Chen, Z.; Jiang, X.; Zhang, X.; Ren, X.; $\mathrm{Qu}, \mathrm{W}$.; et al. Ast1306, a novel irreversible inhibitor of the epidermal growth factor receptor 1 and 2, exhibits antitumor activity both in vitro and in vivo. PLoS One 2011, 6, e21487.

55. Zhang, J.; Cao, J.; Li, J.; Zhang, Y.; Chen, Z.; Peng, W.; Sun, S.; Zhao, N.; Wang, J.; Zhong, D.; et al. A phase I study of ast1306, a novel irreversible egfr and HER2 kinase inhibitor, in patients with advanced solid tumors. J. Hematol. Oncol. 2014, 7, 22. 
56. Berezowska, S.; Diermeier-Daucher, S.; Brockhoff, G.; Busch, R.; Duyster, J.; Grosu, A.L.; Schlegel, J. Effect of additional inhibition of human epidermal growth factor receptor 2 with the bispecific tyrosine kinase inhibitor aee 788 on the resistance to specific egfr inhibition in glioma cells. Int. J. Mol. Med. 2010, 26, 713-721.

57. Evans, A.H.; Pancholi, S.; Farmer, I.; Thornhill, A.; Evans, D.B.; Johnston, S.R.; Dowsett, M.; Martin, L.A. EGFR/HER2 inhibitor AEE788 increases ER-mediated transcription in HER2/ERpositive breast cancer cells but functions synergistically with endocrine therapy. Br. J. Cancer $\mathbf{2 0 1 0}$, 102, 1235-1243.

58. Ako, E.; Yamashita, Y.; Ohira, M.; Yamazaki, M.; Hori, T.; Kubo, N.; Sawada, T.; Hirakawa, K. The pan-erbB tyrosine kinase inhibitor CI-1033 inhibits human esophageal cancer cells in vitro and in vivo. Oncol. Rep. 2007, 17, 887-893.

59. Rixe, O.; Franco, S.X.; Yardley, D.A.; Johnston, S.R.; Martin, M.; Arun, B.K.; Letrent, S.P.; Rugo, H.S. A randomized, phase II, dose-finding study of the pan-erbB receptor tyrosine-kinase inhibitor CI-1033 in patients with pretreated metastatic breast cancer. Cancer Chemother. Pharmacol. 2009, 64, 1139-1148.

60. Jani, J.P.; Finn, R.S.; Campbell, M.; Coleman, K.G.; Connell, R.D.; Currier, N.; Emerson, E.O.; Floyd, E.; Harriman, S.; Kath, J.C.; et al. Discovery and pharmacologic characterization of CP-724,714, a selective ErbB2 tyrosine kinase inhibitor. Cancer Res. 2007, 67, 9887-9893.

61. Munster, P.N.; Britten, C.D.; Mita, M.; Gelmon, K.; Minton, S.E.; Moulder, S.; Slamon, D.J.; Guo, F.; Letrent, S.P.; Denis, L.; et al. First study of the safety, tolerability, and pharmacokinetics of CP-724,714 in patients with advanced malignant solid HER2-expressing tumors. Clin. Cancer Res. 2007, 13, 1238-1245.

62. Cai, X.; Zhai, H.X.; Wang, J.; Forrester, J.; Qu, H.; Yin, L.; Lai, C.J.; Bao, R.; Qian, C. Discovery of 7-(4-(3-ethynylphenylamino)-7-methoxyquinazolin-6-yloxy)- $N$-hydroxyheptanamide (CUDC-101) as a potent multi-acting HDAC, EGFR, and HER2 inhibitor for the treatment of cancer. J. Med. Chem. 2010, 53, 2000-2009.

63. Lai, C.J.; Bao, R.; Tao, X.; Wang, J.; Atoyan, R.; Qu, H.; Wang, D.G.; Yin, L.; Samson, M.; Forrester, J.; et al. CUDC-101, a multitargeted inhibitor of histone deacetylase, epidermal growth factor receptor, and human epidermal growth factor receptor 2, exerts potent anticancer activity. Cancer Res. 2010, 70, 3647-3656.

64. Jimeno, A.; Galloway, T.; Wirth, L.; Gilbert, J.; Saba, N.; Bauman, J.; Colevas, D.; Mehra, R.; Raben, D.; Lai, C.-J.; et al. A phase I study of CUDC-101, a multitarget inhibitor of HDACs, EGFR, and HER2, in combination with chemoradiation in patients with intermediate/high risk locally advanced squamous cell carcinoma of the head and neck. Mol. Cancer Ther. 2013, 12 (Suppl. 11), doi:10.1158/1535-7163.TARG-13-B268.

65. Ishikawa, T.; Seto, M.; Banno, H.; Kawakita, Y.; Oorui, M.; Taniguchi, T.; Ohta, Y.; Tamura, T.; Nakayama, A.; Miki, H.; et al. Design and synthesis of novel human epidermal growth factor receptor 2 (HER2)/epidermal growth factor receptor (EGFR) dual inhibitors bearing a pyrrolo[3,2-d]pyrimidine scaffold. J. Med. Chem. 2011, 54, 8030-8050.

66. Erdo, F.; Gordon, J.; Wu, J.T.; Sziraki, I. Verification of brain penetration of the unbound fraction of a novel HER2/EGFR dual kinase inhibitor (TAK-285) by microdialysis in rats. Brain Res. Bull. 2012, 87, 413-419. 
67. Doi, T.; Takiuchi, H.; Ohtsu, A.; Fuse, N.; Goto, M.; Yoshida, M.; Dote, N.; Kuze, Y.; Jinno, F.; Fujimoto, M.; et al. Phase I first-in-human study of tak-285, a novel investigational dual HER2/egfr inhibitor, in cancer patients. Br. J. Cancer 2012, 106, 666-672.

68. Torres, M.A.; Raju, U.; Molkentine, D.; Riesterer, O.; Milas, L.; Ang, K.K. Ac480, formerly bms-599626, a pan HER inhibitor, enhances radiosensitivity and radioresponse of head and neck squamous cell carcinoma cells in vitro and in vivo. Investig. New Drugs 2011, 29, 554-561.

69. Axelrod, M.J.; Mendez, R.E.; Khalil, A.; Leimgruber, S.S.; Sharlow, E.R.; Capaldo, B.; Conaway, M.; Gioeli, D.G.; Weber, M.J.; Jameson, M.J. Synergistic apoptosis in head and neck squamous cell carcinoma cells by co-inhibition of insulin-like growth factor-1 receptor signaling and compensatory signaling pathways. Head Neck 2014, doi:10.1002/hed.23822.

70. Janne, P.A.; Boss, D.S.; Camidge, D.R.; Britten, C.D.; Engelman, J.A.; Garon, E.B.; Guo, F.; Wong, S.; Liang, J.; Letrent, S.; et al. Phase I dose-escalation study of the pan-HER inhibitor, pf299804, in patients with advanced malignant solid tumors. Clin. Cancer Res. 2011, 17, 1131-1139.

71. Kalous, O.; Conklin, D.; Desai, A.J.; O’Brien, N.A.; Ginther, C.; Anderson, L.; Cohen, D.J.; Britten, C.D.; Taylor, I.; Christensen, J.G.; et al. Dacomitinib (pf-00299804), an irreversible pan-HER inhibitor, inhibits proliferation of HER2-amplified breast cancer cell lines resistant to trastuzumab and lapatinib. Mol. Cancer Ther. 2012, 11, 1978-1987.

72. Reckamp, K.L.; Giaccone, G.; Camidge, D.R.; Gadgeel, S.M.; Khuri, F.R.; Engelman, J.A.; Koczywas, M.; Rajan, A.; Campbell, A.K.; Gernhardt, D.; et al. A phase 2 trial of dacomitinib (pf-00299804), an oral, irreversible pan-HER (human epidermal growth factor receptor) inhibitor, in patients with advanced non-small cell lung cancer after failure of prior chemotherapy and erlotinib. Cancer 2014, 120, 1145-1154.

73. Erlichman, C.; Hidalgo, M.; Boni, J.P.; Martins, P.; Quinn, S.E.; Zacharchuk, C.; Amorusi, P.; Adjei, A.A.; Rowinsky, E.K. Phase I study of ekb-569, an irreversible inhibitor of the epidermal growth factor receptor, in patients with advanced solid tumors. J. Clin. Oncol. 2006, 24, 2252-2260.

74. Rusnak, D.W.; Lackey, K.; Affleck, K.; Wood, E.R.; Alligood, K.J.; Rhodes, N.; Keith, B.R.; Murray, D.M.; Knight, W.B.; Mullin, R.J.; et al. The effects of the novel, reversible epidermal growth factor receptor/erbb-2 tyrosine kinase inhibitor, gw2016, on the growth of human normal and tumor-derived cell lines in vitro and in vivo. Mol. Cancer Ther. 2001, 1, 85-94.

75. Barf, T.; Kaptein, A. Irreversible protein kinase inhibitors: Balancing the benefits and risks. J. Med. Chem. 2012, 55, 6243-6262.

76. Traxler, P.; Allegrini, P.R.; Brandt, R.; Brueggen, J.; Cozens, R.; Fabbro, D.; Grosios, K.; Lane, H.A.; McSheehy, P.; Mestan, J.; et al. AEE788: A dual family epidermal growth factor receptor/erbB2 and vascular endothelial growth factor receptor tyrosine kinase inhibitor with antitumor and antiangiogenic activity. Cancer Res. 2004, 64, 4931-4941.

77. Smaill, J.B.; Showalter, H.D.; Zhou, H.; Bridges, A.J.; McNamara, D.J.; Fry, D.W.; Nelson, J.M.; Sherwood, V.; Vincent, P.W.; Roberts, B.J.; et al. Tyrosine kinase inhibitors. 18. 6-substituted 4-anilinoquinazolines and 4-anilinopyrido[3,4-d]pyrimidines as soluble, irreversible inhibitors of the epidermal growth factor receptor. J. Med. Chem. 2001, 44, 429-440.

78. Morphy, R. Selectively nonselective kinase inhibition: Striking the right balance. J. Med. Chem. 2010, 53, 1413-1437. 
79. Kawakita, Y.; Seto, M.; Ohashi, T.; Tamura, T.; Yusa, T.; Miki, H.; Iwata, H.; Kamiguchi, H.; Tanaka, T.; Sogabe, S.; et al. Design and synthesis of novel pyrimido[4,5- $b]$ azepine derivatives as HER2/EGFR dual inhibitors. Bioorg. Med. Chem. 2013, 21, 2250-2261.

80. Gavai, A.V.; Fink, B.E.; Fairfax, D.J.; Martin, G.S.; Rossiter, L.M.; Holst, C.L.; Kim, S.H.; Leavitt, K.J.; Mastalerz, H.; Han, W.C.; et al. Discovery and preclinical evaluation of [4-[[1-(3-fluorophenyl)methyl]-1h-indazol-5-ylamino]-5-methylpyrrolo[2,1-f][1,2,4]triazin-6-yl]carbamic acid, (3s)-3-morpholinylmethyl ester (bms-599626), a selective and orally efficacious inhibitor of human epidermal growth factor receptor 1 and 2 kinases. J. Med. Chem. 2009, 52, 6527-6530.

81. Fink, B.E.; Norris, D.; Mastalerz, H.; Chen, P.; Goyal, B.; Zhao, Y.; Kim, S.H.; Vite, G.D.; Lee, F.Y.; Zhang, H.; et al. Novel pyrrolo[2,1-f][1,2,4]triazin-4-amines: Dual inhibitors of egfr and HER2 protein tyrosine kinases. Bioorg. Med. Chem. Lett. 2011, 21, 781-785.

82. Sadek, M.M.; Serrya, R.A.; Kafafy, A.H.; Ahmed, M.; Wang, F.; Abouzid, K.A. Discovery of new HER2/egfr dual kinase inhibitors based on the anilinoquinazoline scaffold as potential anti-cancer agents. J. Enzym. Inhib. Med. Chem. 2014, 29, 215-222.

83. Li, D.D.; Qin, Y.J.; Sun, J.; Li, J.R.; Fang, F.; Du, Q.R.; Qian, Y.; Gong, H.B.; Zhu, H.L. Optimization of substituted 6-salicyl-4-anilinoquinazoline derivatives as dual egfr/HER2 tyrosine kinase inhibitors. PLoS One 2013, 8, e69427.

84. Kawakita, Y.; Miwa, K.; Seto, M.; Banno, H.; Ohta, Y.; Tamura, T.; Yusa, T.; Miki, H.; Kamiguchi, H.; Ikeda, Y.; et al. Design and synthesis of pyrrolo[3,2-d]pyrimidine HER2/egfr dual inhibitors: Improvement of the physicochemical and pharmacokinetic profiles for potent in vivo anti-tumor efficacy. Bioorg. Med. Chem. 2012, 20, 6171-6180.

85. Kawakita, Y.; Banno, H.; Ohashi, T.; Tamura, T.; Yusa, T.; Nakayama, A.; Miki, H.; Iwata, H.; Kamiguchi, H.; Tanaka, T.; et al. Design and synthesis of pyrrolo[3,2-d]pyrimidine human epidermal growth factor receptor 2 (HER2)/epidermal growth factor receptor (EGFR) dual inhibitors: Exploration of novel back-pocket binders. J. Med. Chem. 2012, 55, 3975-3991.

86. Zhou, W.; Ercan, D.; Janne, P.A.; Gray, N.S. Discovery of selective irreversible inhibitors for EGFR-T790M. Bioorg. Med. Chem. Lett. 2011, 21, 638-643.

87. Ok, S.; Kim, S.M.; Kim, C.; Nam, D.; Shim, B.S.; Kim, S.H.; Ahn, K.S.; Choi, S.H. Emodin inhibits invasion and migration of prostate and lung cancer cells by downregulating the expression of chemokine receptor cxcr4. Immunopharmacol. Immunotoxicol. 2012, 34, 768-778.

88. Sridhar, J.; Sfondouris, M.E.; Bratton, M.R.; Nguyen, T.L.; Townley, I.; Klein Stevens, C.L.; Jones, F.E. Identification of quinones as HER2 inhibitors for the treatment of trastuzumab resistant breast cancer. Bioorg. Med. Chem. Lett. 2013, 24, 126-131.

(C) 2014 by the authors; licensee MDPI, Basel, Switzerland. This article is an open access article distributed under the terms and conditions of the Creative Commons Attribution license (http://creativecommons.org/licenses/by/3.0/). 